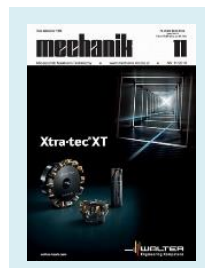

Authors: Jan Burek, Paweł Turek

Title of article: „Ocena dokładności rekonstrukcji geometrii struktury anatomicznej z zastosowaniem tomografii przemysłowej $\mathrm{i}$ głowicy laserowej" ("Analysis of the geometry reconstruction accuracy of the anatomical structure using industrial tomography and laser head")

Mechanik, Vol. 91, No. 11 (2018): pages 973-975

DOI: https://doi.org/10.17814/mechanik.2018.11.173

\title{
Analysis of the geometry reconstruction accuracy of the anatomical structure using industrial tomography and laser head
}

\author{
Ocena dokładnoścl rekonstrukcjl geometrll struktury \\ anatomiczne] z zastosowanlem tomografil przemysłowe] \\ I głowicy laserowe]
}

\section{JAN BUREK PAWEK TUREK *}

The article presents a study of impact a reconstruction method on accuracy of mapping the anatomical structure geometry. At the stage of digitalization process, two systems were used: a measuring arm equipped with a laser head and an industrial tomography.

KEYWORDS: reverse engineering, anatomical structure, computed tomography, laser head, accuracy

Reverse engineering is a process that allows to recreate the geometry of an existing object $[1,2]$. It is used in many fields, including in medicine. The geometry of the anatomical structure model can be reconstructed in two ways in which the measurements are performed on the living body or outside it. Using the medical path, it is possible to reconstruct the geometry of anatomical structures $[3,4]$ and to make surgical templates [5] and ready implants [6]. The nonmedical path is mainly a supplement to the medical path. Coordinated measuring systems used in this path are mainly used to verify the accuracy of models used in the medical industry [7], as well as to design orthoses stabilizing joints [8].

Each stage of the medical and non-medical path influences the accuracy of the reconstruction of the model's geometry. One of the key steps is the acquisition of data - the appropriate selection of the system, parameters and measurement strategy determines the quality of the obtained data $[9,10]$. The stage of data processing usually starts with the process of digital filtration, consisting in removing the noise found in 2D images (in the case of a medical path) and point clouds (in the case of a non-medical path). After filtration, a full model geometry is obtained, however, in the case of a medical path, the segmentation process is additionally performed. It is used to isolate the anatomical structure from 2D images through the use of various methods, based mainly on edge detection and identification of image areas that are characterized by some common features [11].

In both reconstruction methods, the reconstructed geometry is usually triangulated, leading to a faceted surface that requires additional editing, including the reversal of normal vectors and the removal of holes between triangles [11]. The finished model, represented by the faceted surface, can be manufactured using various additive techniques [12,
13]. Further modeling is also possible, consisting in covering the polygonal mesh with elementary surfaces [14]. The obtained model can be exported using various CAD data exchange formats, such as *.iges or *.step, or it can be used to execute a machining program on computer numerical controlled machines [15].

\section{Research methodology}

The geometry of the anatomical structure model, representing the zygomatic bone, was reconstructed on the basis of data from the Siemens Somatom Sensation Open 40 multi-row tomograph. The physical model (fig. 1) was created by the FDM (fused deposition modeling) additive method based on the using of thermoplastic plastic. A Stratasys Fortus 360-mc 3D printer was used for this. The model was printed from ABS plastic (acrylonitrile butadiene styrene) using T16 print heads (both for model and support material). It was decided to fill the internal structures of model completely. Selected heads ensured a layer thickness of the order of $0.254 \mathrm{~mm}$ and model's performance within a tolerance of $\pm 0.13 \mathrm{~mm}[16]$.

The measurements of the model were made using two systems: the Nikon Benchtop CT160Xi industrial tomograph and the MCA II coordinate measuring arm, equipped with the MMDx100 laser measuring head (fig. 2).

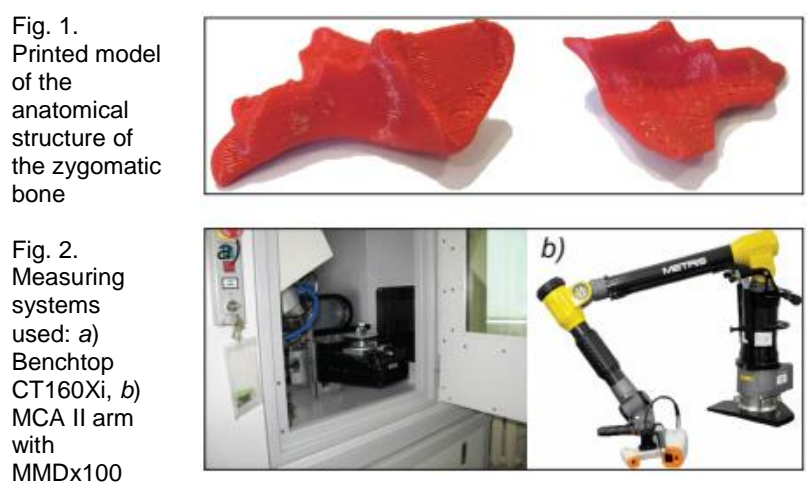


The accuracy of the industrial CT scanner was checked in accordance with the guidelines of the VDI/VDE 2630 Blatt 1.3. standard "Computer tomografie in der dimensionellen Messtechnik" [17,18]. The Benchtop (Nikon) CT160Xi is not factory calibrated. Before each element measurement on this tomograph, it must be checked separately. The process is mainly carried out on the ball bar template. Based on this measurement, the voxel dimension is adjusted to the assumed scan volume, according to the obtained sphere mapping error.

The volumetric data obtained from the measurement, representing the geometry of the zygomatic bone, were characterized by the structure of the iso-voxel - the size of the pixel $0.059 \mathrm{~mm} \times 0.059 \mathrm{~mm}$ and the thickness of the layer $0.059 \mathrm{~mm}$. Each element of the created image is represented by the average radiation attenuation factor in the tissue element of the imaged layer. Such a numerical value in commonly used computed tomography is defined on the Hounsfield scale (HU). The model geometry was reconstructed in the ITK Snap software. On the basis of the CT data, the same value of the segmentation threshold was chosen, equal to $210 \mathrm{HU}$. In relation to it, thresholding segmentation was performed. To illustrate the 3D model, the iso-surface method, which is part of the surface rendering

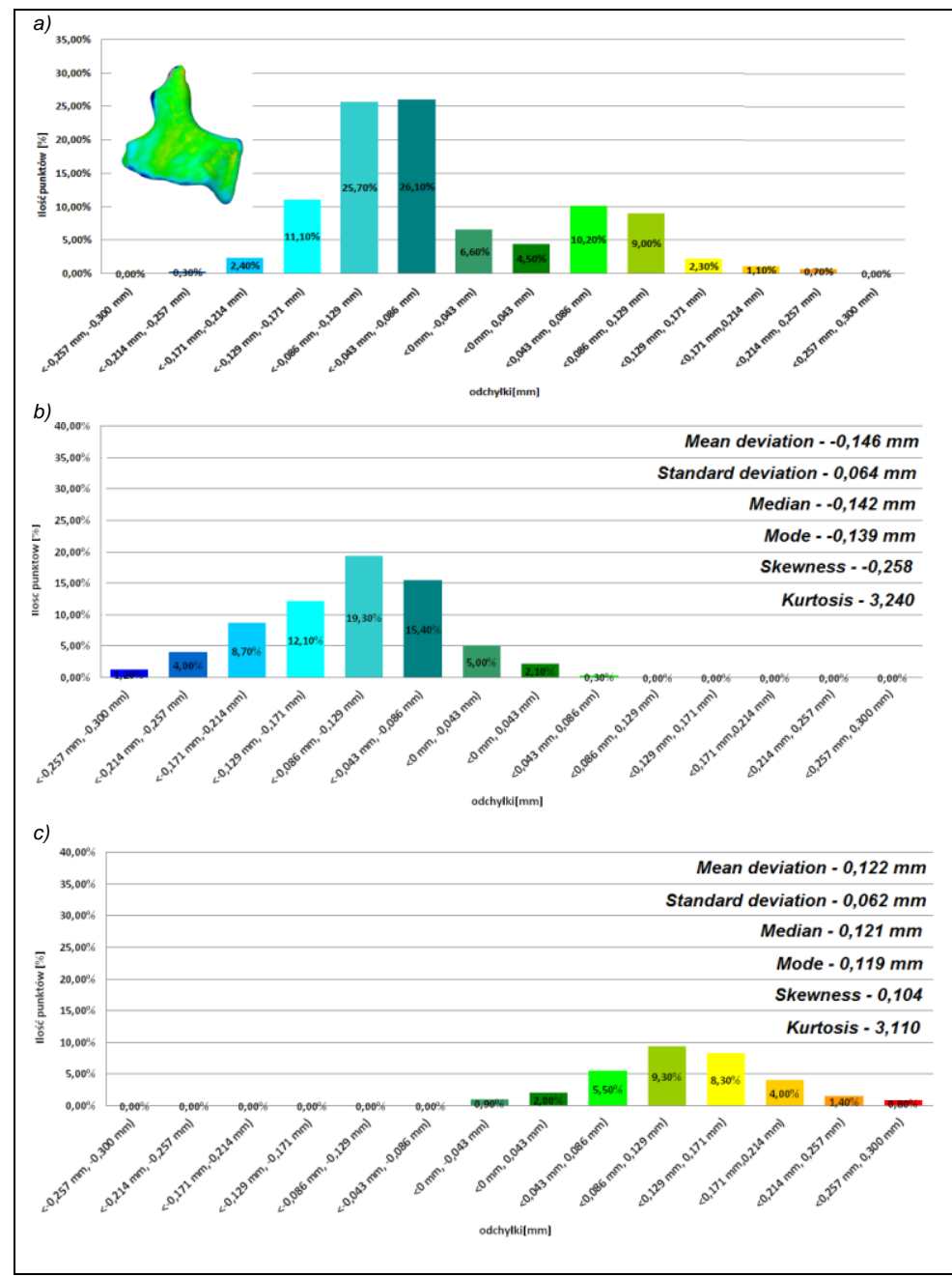

Fig. 3. Model accuracy report (industrial tomograph): a) bimodal distribution, $b$ ) first distribution, $c$ ) second distribution

\section{Results}

Obtained histograms show bimodal distributions (fig. 3a and fig. 4a), characterized by two maxima. In this case, the measures calculated on the basis of these data (mean, standard deviation, asymmetry, kurtosis) have no cognitive value. Therefore, two distributions were separated using the regression function for a curve characterized by methods, was used. In order to check the repeatability of the measurement process, it was repeated three times. The measurements differed from each other with the value of standard deviation - from 0.02 to $0.03 \mathrm{~mm}$.

The measurement system that illuminated the model with a laser beam, in addition to the MMDx100 head, also included the seven-axis MCA II measuring arm. Due to the fact that a laser head was mounted on the measuring arm, it was necessary to take into account common errors of the armhead system $[19,20]$. The accuracy of the coordinate measuring arm was checked against ASME B89.4.22. When measuring the model, a resolution of $0.05 \mathrm{~mm}$ was used. They were carried out in two stages: first the external part was measured and then - the internal part of the model. The next stage was the edition of the surface model in the CATIA program (in the STL Rapid Prototyping module). The finished model was created as a result of fitting two point clouds in the Focus Inspection program. After verifying the repeatability of the adopted measurement procedure, it turned out that the maximum difference of standard deviations for the external surface was $0.040 \mathrm{~mm}$, and for the internal surface -0.054 $\mathrm{mm}$. The average value of the fit accuracy of two measured parts in the Focus Inspection program was $0.1 \mathrm{~mm}$.

more than one maximum. This allowed, among others to fit the curve to the sum of Gaussian functions. First the number of maxima was determined and then the position of each maximum on the curve was defined. As a result of the function, two normal distributions were obtained, which were used for further analyzes.

In the case of data from industrial tomograph measurements, a higher concentration of deviations in the range from $-0.129 \mathrm{~mm}$ to $-0.043 \mathrm{~mm}$. They can be seen primarily on the edges of the model's geometry. These deviations may have occur as a result of the occurrence during the measurement of the artifact (partial volume effect), which consists in averaging an element located geometrically at the border of two areas (e.g. object and background). The boundary of the object on the 2D image is then barely visible, which hindered the determination of the lower threshold of segmentation at the stage of segmentation of the zygomatic bone model.

Distributions are characterized by negative skew (fig. 3b) and positive skew (fig. 3c). In addition, this is confirmed by the values of the mean deviation, dominant and median. On the basis of the obtained kurtosis it can be concluded that both distributions are leptokurtic.

In the case of data from measurements using the measuring arm-laser head system one can observe some analogy to the data presented in fig. 3 .

There is also a bimodal distribution, but the percentage distribution of deviations with a negative and a positive value is proportional, symmetrically distributed with respect to the central part of the histogram. Deviations mainly are in the range from $0.129 \mathrm{~mm}$ to $-0.043 \mathrm{~mm}$ and from $0.043 \mathrm{~mm}$ to 0.129 $\mathrm{mm}$. Both distributions (fig. $4 \mathrm{~b}$ and fig. 4c) are characterized by positive skew. The kurtosis confirms that both distributions are leptokurtic. 


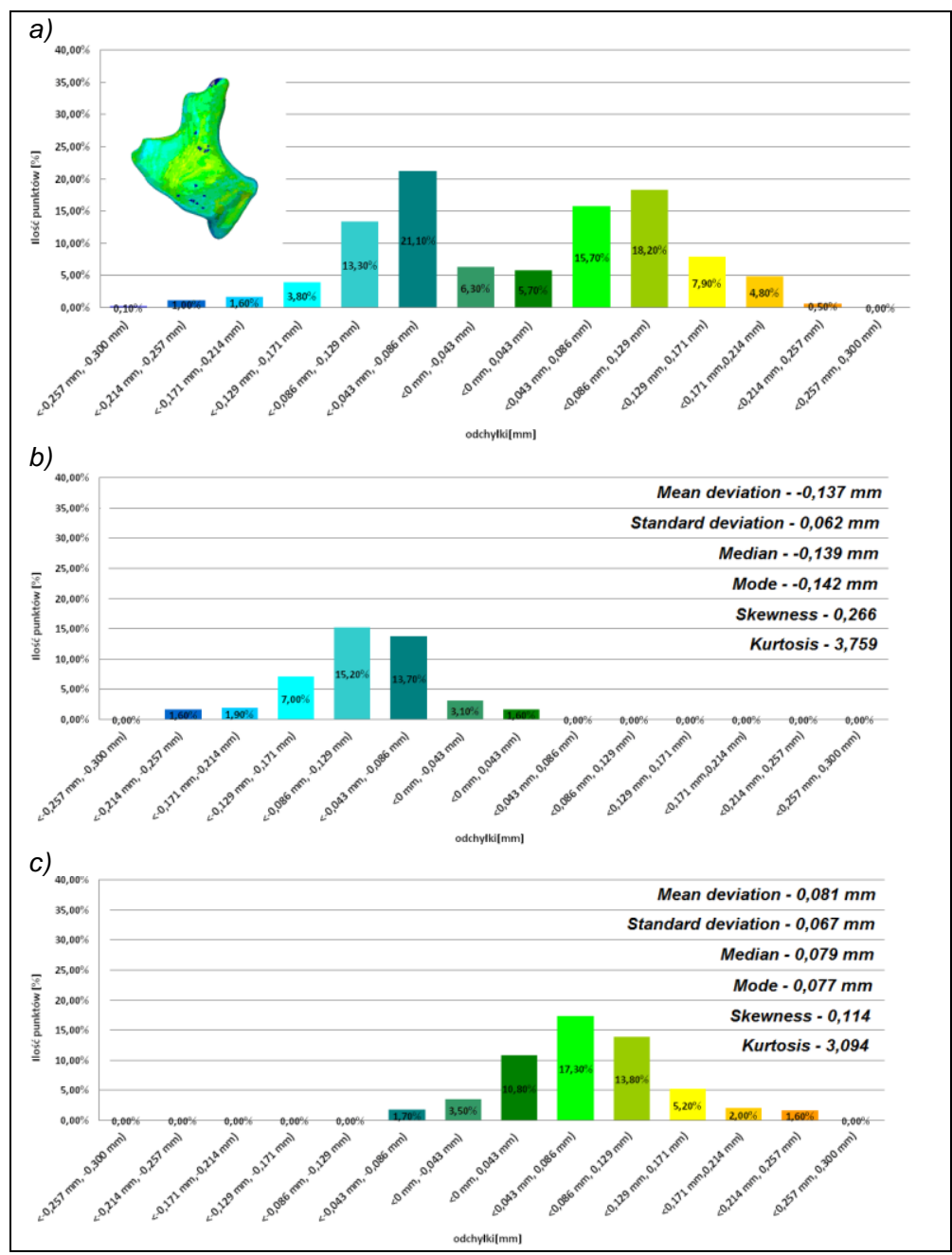

Obtaining a bimodal distribution in the case of the arm-laser head system could be related to the formation of over-scans during the measurement process and the fitting of two parts (external and internal) of the measured model in order to reconstruct the full geometry of the zygomatic bone.

\section{Conclusions}

The process of reverse engineering plays an increasingly important role in medicine. The use of measuring systems, data processing methods and manufacturing techniques allows us to reconstruct the geometry of anatomical structure model and verify the accuracy of its implementation. Anatomical medical models significantly reduce the time of surgery and reduce the risk of intraoperative complications. The accuracy of the anatomical medical models depends on many factors, including the selection of the measurement system.

Based on the obtained results, it can be stated that in the case of reconstruction of the model from $2 \mathrm{D}$ images data, the selection of the segmentation threshold has the main influence on the accuracy of the geometry. On the other hand, in the case of the laser head-arm system, the errors generate the measurement and the fitting process of the point clouds.

distribution, $b$ ) first distribution, $c$ ) second distribution

\section{REFERENCES}

1. Gibson I., Rosen D.W., Strucker B. "Additive manufacturing technologies: Rapid prototyping to direct digital manufacturing”. Springer, 2010.

2. Raja V., Kiran J.F. "Reverse Engineering - An Industrial Perspective". Springer Series in Advanced Manufacturing, 2010.

3 . Bidanda, B., Bartolo P. "Virtual prototyping \& bio manufacturing in medical applications". Springer, 2008.

4. Gebhardt A. „Rapid prototyping”. Hanser Gardner Publications, 2003.

5. Budzik G., Burek J., Dziubek T., Markowska O., Turek .P., Pakla P "Applications of rapid prototyping technology in the craniofacial surgery". Mechanika w Medycynie. 12 (2014): pp. 16-29.

6. Ciocca L. I in. "A CAD/CAM-prototyped anatomical condylar prosthesis connected to a custom-made bone plate to support a fibula free flap". Medical \& Biological Engineering \& Computing. 50, 7 (2012): pp. 743 749.

7. Budzik G., Burek J., Bazan A., Turek P. "Analysis of the accuracy of reconstructed two teeth models manufactured using the 3DP and FDM technologies". Stroj Vestn: JMech E. 62, 1 (2016): pp. 11-20.

8. Baronio G., Harran S., Signoroni A. "A Critical Analysis of a Hand Orthosis Reverse Engineering and 3D Printing Process". Applied Bionics and Biomechanics. Hindawi, 2016.

9. Barbero B.R., Ureta E.S. "Comparative study of different digitization techniques and their accuracy". Computer-Aided Design. 43, 2 (2011): pp. 188-206.

10. Romans L. "Computed Tomography for Technologists: A Comprehen sive Text". Wolters Kluwer Health Lippincott Williams \& Wilkins, 2011.

11. Huotilainen E., Jaanimets R., Valášek J., Marcián P., Salmi M., Tuomi J., Mäkitie A., Wolff J. "Inaccuracies in additive manufactured medical skull models caused by the DICOM to STL conversion process". Journal of Cranio-Maxillofacial Surgery. 45, 5 (2014): pp. e259-e265.

12. Nizam A., Gopal R.N., Naing L., Hakim A.B., Samsudin A.R. "Dimensional accuracy of the skull models produced by rapid prototyping technology using stereolithography apparatus". Arch Orofac Sci. 1 (2006): pp. 60-66.
13. Safira L.C., Bastos L.C., Estev V., de Azevedo R.A., Francischone C.E., Sarmento V.A. "Accuracy of rapid prototyping biomodels plotted by three dimensional printing technique: ex vivo study". Advances in Computed Tomography. 2, 2 (2013): pp. 41-45.

14. Yoo D.J. "Three-dimensional surface reconstruction of human bone using a B-spline based interpolation approach". Computer-Aided Design. 43, 8 (2011): pp. 934-947.

15. Budzik G., Burek J., Dziubek T., Gdula M., Płodzień M., Turek P. “The analysis of accuracy zygomatic bone model manufactured by 5 -axis HSC 55 linear". Mechanik. 96, 2 (2015), CD.

16. Hanssen J. "FORTUS 360mc/400mc ACCURACY STUDY", www.stratasys.com (access from:18.03.2013).

17. Ryniewicz A., Ostrowska K., Knapik R., Ryniewicz W., Krawczyk M., Sładek J., Bojko Ł. „Ocena odwzorowania wybranych parametrów geometrycznych w tomografii komputerowej z zastosowaniem wzorców". Przegląd Elektrotechniczny. 91, 6 (2015): pp. 88-91.

18. Kowaluk T., Ratajczyk E. „Sprawdzanie dokładności przemysłowych tomografów komputerowych". Mechanik. 97, 11 (2016): pp. 171-178.

19. Ratajczyk E., Koperska A. „Porównanie testów dokładności współrzędnościowych ramion pomiarowych". Mechanik. 91, 8-9 (2010): pp. 588-594.

20. Ratajczyk E., Adamczyk A. „Porównanie dokładności wybranych skanerów laserowych". Mechanik. 96, 12 (2015): pp. 945-948. .

Translation of scientific articles, their computer composition and publishing them on the website www.mechanik.media.pl by original articles in Polish is a task financed from the funds of the Ministry of Science and Higher Education designated for dissemination of science. 